\title{
The Impact of Communication Campaigns on the Organizational Identity
}

\author{
Adelina PRICOPE ${ }^{\star}$, Nicolae Viorel TRIF ${ }^{\star \star}$, Mihaela NECULITA ${ }^{\star \star \star}$, \\ Irina Olimpia SUSANU $U^{\star \star \star \star}$
}

\begin{tabular}{l}
\hline \multicolumn{1}{c}{ A R T I C L E I N F O } \\
\hline Article history: \\
Accepted December 2018 \\
Available online April 2019 \\
\hline JEL Classification \\
M30, M31, M37 \\
Keywords: \\
Identity, Communication, \\
Campaigns, Promotional policy
\end{tabular}

\begin{abstract}
A B S T R A C T
Organizational identity is a key element in a continuous exploration and definition, where the need to be defined as well as possible is continuous. This paper sets forth the factors of impact on the organizational identity from the communication campaigns viewpoint. The manner in which a brand tries to "communicate" with the target audience, and to convince of its qualities, is a present-day subject, with many resources to exploit. It is precisely for this reason that the need for this article has appeared, trying to bring new methods of identity strengthening, in addition to those already known.
\end{abstract}

(c) 2019 EAI. All rights reserved.

\section{Introduction}

Communication campaigns are part of the promotional policy. This being a component of the company's marketing policy, it is very important since it ensures the permanent connection of the company with the market where it operates. Without this permanent connection (receiving and transmitting information), the company's marketing policy is doomed to failure and the company will disappear from the market. (Webography 1 )

In close relation with the components of the marketing strategy, the question arises of the communication system associated with the modern organization. This issue is still a battle ground among specialists. While some authors place the communication system, especially within the promotional policy, others believe that this has components that are also found in product policy, pricing policy or distribution policy. (Popescu 2001)

In order to clarify these issues, we will highlight a few concepts concerning communication and communication policy.

Ioana Popescu, Marketing Specialist, defines communication as being (Popescu 2002) a new management concept that has evolved especially over the last two decades of the twentieth century. It has received more and more importance in the activity of the organizations. Through this it is built the bridge among the organization and employers, customers, suppliers, or other categories of the public. Although the modern forms of marketing communication have made their presence felt relatively recent, they have appeared even since Plato's time, public speeches aiming to reach goals specific to public relations.

Another point of view regarding communication is given by V. Balaure (2003), which says that communication itself can also be defined as a system made up of: the transmitter- also named the source of communication, respectively the one that sends the message; coding - corresponds to the mechanism that "translates" the ideas of the message into symbols, signs, images; the message - the entirety of symbols; media - destination, decoding - is the significance assigned to the message by the receiver; receiver - also called audience or recipient; the response - includes all reactions of the audience; feedback - the part of the response which the receiver resends to the transmitter, and the disturbing element - anything can cause a distortion between the emitted and the received message.

In the view of Petre Dătculescu (2006), the purpose of researching communication is to supplement, but not replace the creative act of the advertising agency. He also says that marketing communications are some means by which companies are trying to inform consumers, both directly and indirectly, on the products and brands they trade. The goals of communication research are: to ensure the development of creative ideas and elements involved in creative executions, by identifying strengths and weaknesses; to help the advertising agency understand better how to modify the creative concept. 
The word 'communication' comes from the Latin "communis" which means common. Beside a dictionary explanation defining the word communication, as meaning "to make known, to let know, to inform, to notify, to say," and communication as "the action to communicate and its outcome"; there are many other definitions of the communication process, definitions found in many papers on sociology or marketing.

Philip Kotler reckons that the core element of marketing communications is advertising. This is an element that makes up the mix of marketing communications. "The mix of marketing communications includes six main ways of communication: commercial advertising (through paid advertising); sales promotion; organized events and experiments; public relations and propaganda (non-commercial advertising); direct marketing; personal sale"(Kotler 2008)

David Ogilvy (1985) believes that advertising is not an entertainment or art, but a means of information. "When I write an ad text I do not want to be considered a 'creative' person. I want it to be so interesting that to determine the purchase of the product. " However, advertising cannot be regarded as being exclusively informative (Abad 1992). The communication valences of advertising are supported by the subjectivism and partisanship of this technique which, by means of specific methods, acts on the human psyche not only at cognitive level, but also at affective and cognitive level, pursuing to give rise to an attitude and behavior in favor of the element being the object of the communication.

Some authors have classified the communication into two categories, namely: promotional communication that includes, at the level of methods or techniques of communication it appeals to, advertising, sales promotion, public relations, sales force and direct marketing (Balaure 1994), and the second category refers to continuous communication including techniques of continuous communication, such as brand, design and packaging, architectonics, and so on. Therefore, it can be concluded that, as a whole, marketing communication refers both to the constitutive elements of promotional policy and to those related to product policies (for example, brand, packaging, etc.), price and distribution. In other words, the communication system of modern organization has a synergistic effect of the entire marketing system, described by taking into account all components of the marketing strategy.

\section{Methodology}

In order to highlight the communication campaigns impact on the organizational identity, we carried out a study from 11.11.2018 to 03.12 .2018 on a random sample of 74 respondents, persons with different demographic situations, wishing to be able to cover a wide range of consumers.

The questionnaire was sent to the entire target group through the Facebook Social Network and on the website http://www.isondaje.ro, being filled in online by the questioned.

\section{Common and differentiation points of the communication campaigns}

During the analyses of promotional campaigns, we could note that each company uses a set of tools specific to promotion, which will help in achieving the intended goals. In order to outline the importance of each tool, in Table 1 we displayed the advertising tools used by each company in the previously-exemplified promotional campaigns.

Table 1 Common and differentiation points of campaigns analyzed from the communication point of view

\begin{tabular}{|l|c|c|c|}
\hline \multicolumn{1}{|r|}{ Brand } & Bergenbier & Domestos & British American Tobacco \\
Promotion tool & $\mathrm{X}$ & $\mathrm{X}$ & \\
\hline Printed advertisements & $\mathrm{X}$ & $\mathrm{X}$ & $\mathrm{X}$ \\
\hline TV advertisements & & $\mathrm{X}$ & $\mathrm{X}$ \\
\hline Inserts inside the package & $\mathrm{X}$ & $\mathrm{X}$ & $\mathrm{X}$ \\
\hline Promotional flyers & $\mathrm{X}$ & $\mathrm{X}$ \\
\hline Advertising panels & $\mathrm{X}$ & $\mathrm{X}$ & \\
\hline Posting & $\mathrm{X}$ & $\mathrm{X}$ & $\mathrm{X}$ \\
\hline Competitions & $\mathrm{X}$ & $\mathrm{X}$ & \\
\hline Prizes and gifts & $\mathrm{X}$ & $\mathrm{X}$ & \\
\hline Sponsorships & \multicolumn{2}{|c|}{ Source: own processing } \\
\hline Sales presentations & & \\
\hline
\end{tabular}

From the previous table, we notice that all brands appeal intensively to the promotion tools specific to advertising, promotions, public relations, but also to sales force. 
The common ways of promoting the three brands are determined by promotion through competitions, prizes and gifts and sales presentations.

For sure British American Tobacco would have also used other promotional methods if it had the possibility, but the limitations imposed by law do not allow this. However, BAT manages to maintain leadership in its field by the few tools it uses, which means that their use is done with a sense of responsibility and maximum efficiency.

It is important that all three companies periodically review their advertising programs so as to attract new market segments and gradually highlight a qualitative approach that would be oriented towards reaching the goals.

After unfolding these campaigns, the representatives of the companies made visits to the shops where the activity was carried out in order to request the sales reports. These reports, in the given cases, were the last step for the results measurability, since before their collection there have also been visits of certain mysterious customers to check if the sales force is sending the appropriate message, but also the request for qualitative feedback from the force sale.

Thus, each company, through its own methods, analyzed the campaign progress from several points of view, subsequently communicating to the employees the results obtained, with a view to improving the performance of a future activity, but also to motivating the representatives.

From the data communicated, in the analyzed campaigns there have been taken into account several aspects concerning:

- Sales target - calculated by requesting reports from the locations where it has been held the promotional activity

- Target audience objective - arising from the reports filled in by promoters, where customers are asked for their age

- Quantitative feedback - is the ratio between sales and the number of participants in the promotion

- Qualitative feedback - is made by telephone through the agency of special consultants, through the collected database

- Database trustworthiness - correlated with qualitative feedback, the difference is that for qualitative feedback people are randomly contacted, while in case of checking if the database coincides with reality, all the participants to the campaign are contacted.

- goals achievement - is also the most important item, where all the previous results are quantified and correlated with the objectives established initially.

From internal communications, the campaigns carried out had predominantly positive results, as we will see in the following diagrams.

Table 2 Common and differentiation points of campaigns analyzed from the results point of view

\begin{tabular}{|l|r|r|r|}
\hline BRAND & BERGENBIER & \multicolumn{1}{|c|}{ DOMESTOS } & $\begin{array}{c}\text { BRITISH AMERICAN } \\
\text { TOBACCO }\end{array}$ \\
\hline SALES TARGET & $100 \%$ & $135 \%$ & $100 \%$ \\
\hline TARGET AUDIENCE OBJECTIVE & $80 \%$ & $100 \%$ & $60 \%$ \\
\hline QUANTITATIVE FEEDBACK & $100 \%$ & $100 \%$ & $60 \%$ \\
\hline QUALITATIVE FEEDBACK & $80 \%$ & $80 \%$ & $70 \%$ \\
\hline DATABASE TRUSTWORTHINESS & $90 \%$ & $90 \%$ & $85 \%$ \\
\hline GOALS ACHIEVEMENT & $100 \%$ & $100 \%$ & $80 \%$ \\
\hline
\end{tabular}

The dark red color within the table represents the weaknesses of the companies, where it is required a change of approach.

$>$ The light red color is also specific to campaign weaknesses.

$>$ The light green color represents a balance relationship, where the goals have been successfully reached.

$>$ The dark green is represented by strong points, which must be taken into account and further turned to account in the future. 
Figure 1 plots the positioning of each campaign in terms of results, where we can observe that the differences are not very high, and the reasons why they exist are also given by the limitation that British American Tobacco has in promoting its products.

Figure 1 Results of the promotional campaigns

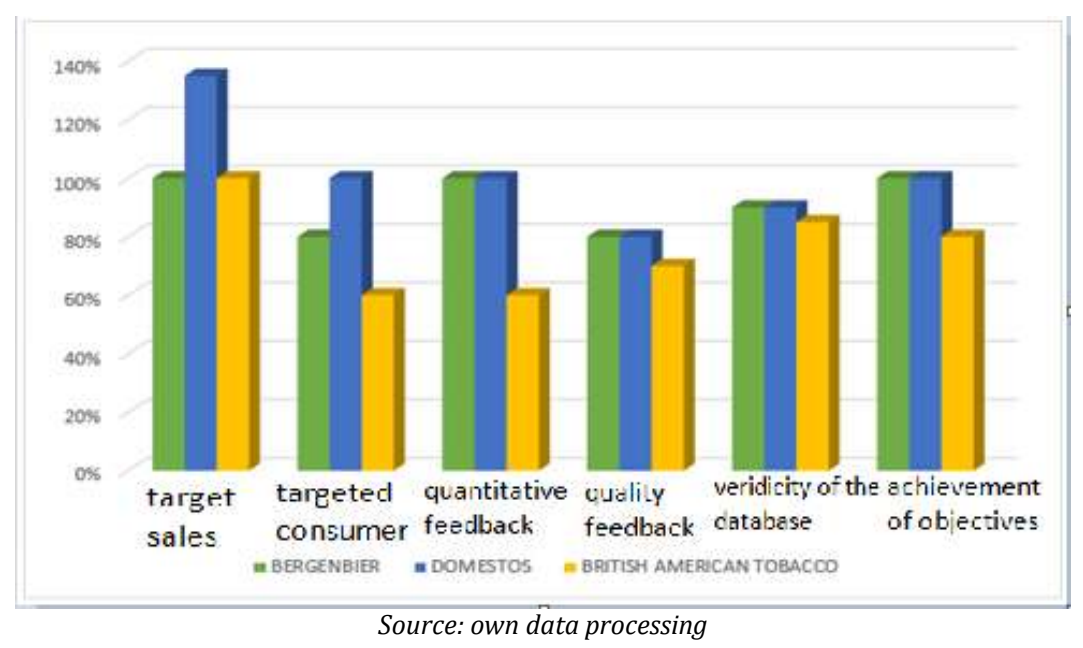

\section{Study concerning the impact of communication campaigns on organizational identity}

In order to underline the impact of communication campaigns on organizational identity, we performed a study between 11.11.2018 and 03.12.2018 on a random sample of 74 respondents with different demographic situation, wanting to be able to cover an as broad as possible spectrum of consumers.

The questionnaire was sent to the entire target group via the Facebook Social Network and the http://www.isondaje.ro website, being completed online by the questionnaires.

After filling in the survey, it resulted a demographic arrangement of $64 \%$ of women and $36 \%$ of men. In terms of age, it resulted an average age arrangement of 31.2 years. The surveyed people come especially from the urban environment, having monthly earnings on the average falling "under RON 2500". It should also be mentioned that the percentage in the occupation is almost equally distributed between students and employees.

\section{Results obtained}

The first part of the questionnaire includes a set of 6 closed answer questions intended to identify the most frequent promotional means met by respondents.

By quantifying the answers of the questionnaires we obtained the following results: $81.3 \%$ of respondents use to pursue promotion campaigns, meeting:

$>$ Advertising (TV, radio, flyers, advertisements, news, etc.) - 30.4\%

$>$ Promotions (competitions, prizes, gifts, samples, remnants, rebates) $-30.4 \%$

$>$ Public relations (seminars, sponsorships, company magazine, events) $-10.9 \%$

$>$ Sales force (sales presentations, fairs and trade fairs) $-6.5 \%$

$>$ Direct marketing (catalogs, correspondence, TV shopping) $-21.7 \%$

$>76.9 \%$ of the respondents stated that the preferred promotional medium out of those listed is given by the communication through promotions.

$>$ In question number 4 , the respondents were asked to agree on the following statements:

The advertisement of a product influences my purchasing decision

\begin{tabular}{|l|c|}
\hline Total disagreement & $0 \%$ \\
\hline Disagreement & $0 \%$ \\
\hline Unresponsive & $31.3 \%$ \\
\hline Agreement & $62.5 \%$ \\
\hline Total agreement & $6.3 \%$ \\
\hline
\end{tabular}

Radio commercials are useful

\begin{tabular}{|l|c|}
\hline Total disagreement & $6.3 \%$ \\
\hline Disagreement & $12.5 \%$ \\
\hline Unresponsive & $50 \%$ \\
\hline Agreement & $25 \%$ \\
\hline
\end{tabular}




\begin{tabular}{|l|r|}
\hline Total agreement & $6.3 \%$ \\
\hline
\end{tabular}

I read the leaflets that I receive

\begin{tabular}{|l|c|}
\hline Total disagreement & $0 \%$ \\
\hline Disagreement & $0 \%$ \\
\hline Unresponsive & $18.8 \%$ \\
\hline Agreement & $75 \%$ \\
\hline Total agreement & $6.3 \%$ \\
\hline
\end{tabular}

I look at the billboards in town

\begin{tabular}{|l|c|}
\hline Total disagreement & $0 \%$ \\
\hline Disagreement & $6.7 \%$ \\
\hline Unresponsive & $33.3 \%$ \\
\hline Agreement & $53.3 \%$ \\
\hline Total agreement & $6.7 \%$ \\
\hline
\end{tabular}

I buy a product only to participate in the promotion

\begin{tabular}{|l|l|}
\hline Total disagreement & $6.3 \%$ \\
\hline Disagreement & $18.8 \%$ \\
\hline Unresponsive & $25 \%$ \\
\hline Agreement & $37.5 \%$ \\
\hline Total agreement & $12.5 \%$ \\
\hline
\end{tabular}

I buy a product only to participate in a competition

\begin{tabular}{|l|c|}
\hline Total disagreement & $6.3 \%$ \\
\hline Disagreement & $18.8 \%$ \\
\hline Unresponsive & $31.3 \%$ \\
\hline Agreement & $37.5 \%$ \\
\hline Total agreement & $6.3 \%$ \\
\hline
\end{tabular}

I ask for samples before purchasing a product

\begin{tabular}{|l|c|}
\hline Total disagreement & $6.3 \%$ \\
\hline Disagreement & $6.3 \%$ \\
\hline Unresponsive & $56.3 \%$ \\
\hline Agreement & $31.3 \%$ \\
\hline Total agreement & $0 \%$ \\
\hline
\end{tabular}

I participate in sales presentations

\begin{tabular}{|l|c|}
\hline Total disagreement & $18.8 \%$ \\
\hline Disagreement & $31.3 \%$ \\
\hline Unresponsive & $31.3 \%$ \\
\hline Agreement & $18.8 \%$ \\
\hline Total agreement & $0 \%$ \\
\hline
\end{tabular}

The companies being sponsors are reliable

\begin{tabular}{|l|l|}
\hline Total disagreement & $6.3 \%$ \\
\hline Disagreement & $6.3 \%$ \\
\hline Unresponsive & $37.5 \%$ \\
\hline Agreement & $43.8 \%$ \\
\hline Total agreement & $6.3 \%$ \\
\hline
\end{tabular}

The following question outlines that people are really interested in promotional campaigns, 87.5\% expressing their wish to participate in an unspecified brand campaign.

The last question in this section underlines that respondents are generally influenced by the features offered by the product. 


\begin{tabular}{|l|c|}
\hline Characteristics of the product/service I benefit from & $81.3 \%$ \\
\hline Gratuitousness that is offered to me & $18.8 \%$ \\
\hline The brand it offers & $0 \%$ \\
\hline Period of the campaign & $0 \%$ \\
\hline Others & $0 \%$ \\
\hline
\end{tabular}

The second part of the questionnaire aims to highlight the effectiveness of some promotional campaigns carried out at a certain time, and how they remained impressed in the consumers' minds. Thus, when they have been asked to associate the brands with the advertising slogan, the following data resulted:

- "It makes my mouth water" has been associated as follows: Caroli $75 \%$, Primola $12.5 \%$, Ursus $12.5 \%$

- $\quad$ "Friends know why " has been associated $100 \%$ with the Bergenbier brand

- "Always over expectations " has been associated with Altex 25\%, Domo 12.5\%, Flanco 31.3\%, Billa 31.3\%

Also, the phrase "For your health, avoid excess of salt, sugar and fat!" was $100 \%$ associated with the promotional campaigns made by TV commercials.

In order to strengthen the method of highlighting the effectiveness of promotional campaigns, we also asked respondents to associate campaigns with the specific brand.

- The campaign "I am 12" - has been 25\% associated with Ursus, $68.8 \%$ with Bergenbier and $6.3 \%$ with Beck's.

- The campaign "I am beautiful" has been $37.5 \%$ associated with Nivea, $18.8 \%$ with Always and $43.8 \%$ with Dove.

- "Supports the hygiene of 10" has been 31.3\% associated with Cif, Duck- 25\%, Domestos 43.8\%. following

In associating the Fanta logo with the places where they met it, the respondents specified the

\begin{tabular}{|l|c|}
\hline On the packaging & $46.9 \%$ \\
\hline On TV & $18.8 \%$ \\
\hline In flyers & $9.4 \%$ \\
\hline On posting/billboards & $9.4 \%$ \\
\hline On the internet & $12.5 \%$ \\
\hline In other places & $3.1 \%$ \\
\hline
\end{tabular}

The advertising panel displayed in the questionnaire triggered the following reactions:

- I must drink Coca-Cola - 68.8\%

- Does anyone drink through a straw?- $6.3 \%$

- What an interesting advertising !- $18.8 \%$

Finally, in the last question respondents claimed that when they meet a promoter in the supermarket have the following reactions:

- I stop to listen to what he/she has to say $81.3 \%$

- I avoid the promoter so as to not be approached $18.8 \%$

\section{Conclusions of the study}

First of all, the most important conclusion we can draw following the results quantification is that the impact of communication campaigns on shaping organizational identity is extremely powerful among consumers of goods and services. This is endorsed by the high percentages that reveal the presence of communication campaigns in various forms of the consumer's life.

Also, the respondents, who in our case are the voice of the society, admit that they are influenced by advertisements in their decision to buy, that they pay attention to the ways in which organizations communicate (flyers, radio, billboards, etc.), from which it follows that the lack of these ways would make them much more difficult to make a decision regarding any purchase. In other words, the presence of promotional means in the life of consumers is a positive thing, the consumers intentionally accepting to be influenced through them.

Another important aspect to be mentioned is the impact of promotional campaigns through the constant presence of brands on the market. Strong brands that have remained stuck in the consumers' minds used slogans with subjective emotional impact, associating the product promoted with various elements. A successful example for that purpose is Bergenbier, which was $100 \%$ associated with the specific slogan, which means that all the communication methods used so far have been extremely effective. We can not say the same thing about the Flanco slogan "Always beyond expectations", as it was easily confused with 
competing companies, and it certainly was not the goal of the company. This means that Flanco needs to work more on the means of communication.

In other news, communication campaigns, even though they are sometimes pursued passively, have audiences and enjoy public recognition. The "I am 12", "I am Beautiful" and "Support hygiene of 10" campaigns have been recognized in a percentage of more than $50 \%$ and, compared to the slogans that are heard permanently, this type of campaign unfolds for a fixed period time, making it more difficult to remember or associate them with certain brands.

Last but not least, every consumer needs a stimulus. He/she will never be fascinated by a product he has never heard about, will never go to choose the products in the lower shelves of supermarkets that are perceived as "no name". We consumers want to be aroused our curiosity, to see on the block of flats a big bottle of cola with a straw coming on the window, to be approached by promoters, in other words, we want all the means of communication existing in our lives. It is precisely why all big companies are in full ascension program as concerns means of communication and are investing more and more in marketing specialists to direct them to success.

\section{Conclusions}

A company should define a basic marketing strategy, preparing its most powerful marketing mix. The word 'mix' is well chosen taking into account the large number of elements that need to be considered, chosen and harmonized.

The most important element of the $4 \mathrm{P}$ mix is given by promotion, since in vain a product is launched at a good price and benefits from an advantageous distribution if the consumer does not find the differentiation term for a similar product. Promoting is the manner in which it is created the permanent connection of the company with the market, a connection without which the company would easily disappear from the market.

The research of promotional communication ensures the development of creative ideas and elements involved in creative executions by identifying strengths and weaknesses; to help the advertising agency understand better how to change the creative concept.

We can distinguish two types of communication: promotional communication that includes, at the level of methods or techniques of communications to which it appeals to, advertising, sales promotion, public relations, sales force and direct marketing, and continuous communication that includes continuous communication techniques such as brand, design and packaging, architectonics and others.

Promotional activities can be structured as follows: Advertising; Sales promotion; Public relations; Use of brands; Promotional events; Force sales.

The promotional strategy is a combination of actions and means subordinated to the objectives of the global marketing policy of the enterprise and designed to contribute to their achievement.

The particular complexity of the promotional activity, as well as its close connection to all the other marketing activities require a special attention in the elaboration of the promotional mix and, thus, implicitly, in choosing the best strategies and tactics for the implementation of what the company has proposed.

\section{References}

1. Balaure,Virgil (2003), Marketing, Ediția a II-a, Editura Uranus, București

2. Dătculescu, Petre (2006), Cercetarea de marketing, Editura Brandbuilders Group, București

3. Kotler, Philip and Keller, Kevin Lane (2008), Managementul marketingului. Ediţia a V-a, Editura Teora. București

4. David Ogilvy (1985), Ogilvy on advertising, Random House, Ney York, USA

5. Valerie Abad, Isabelle Compiegne (1992), Langage et publicite. Lexique de communicationpublicitaire,Breal, Rosny

6. Balaure, V., Popescu,I.C., Șerbănică,D., Tehnici promoționale, Editura Metropol, București,1994

7. https://www.scribd.com/doc/134188927/Cap-6-Politica-Promotionala-pdf 05.04.2013

8. https://ro.wikipedia.org Bergenbier, 11.05.2016

9. https://www.unilever.ro, Unilever în România

10. https://www.domestos.ro, Igiena de 10 în școli

11. https://www.youtube.com, Reclama Domestos, 22.09.2015

12. http://www.jurnaluldeafaceri.ro, BAT povestea unui succes, Uploadat la 01.08.2014

13. http://savexlaundry.com/ro 